\title{
USING TRANSIENT CONSERVATIVE AND ENVIRONMENTAL TRACERS TO STUDY WATER EXCHANGE IN LAKE ISSYK-KUL
}

\author{
R. KIPFER and F. PEETERS \\ Environmental Isotopes Group, Dept.of Water Resources and Drinking \\ Water (W\&T), Swiss Federal Institute of Environmental Science and \\ Technology (EAWAG) \\ CH-8600 Dübendorf, Switzerland
}

\section{Introduction}

Mixing and transport processes are of major importance for the ecology of lakes [1]. In particular, deep-water renewal determines to a large extent the distribution of nutrients and dissolved oxygen in deep lakes such as Lake Issyk-Kul (Kyrgyzstan). The characterization and quantification of deep-water exchange is therefore essential for the understanding of the functioning of such lake ecosystems.

Rates of vertical water exchange can be estimated from concentrations of transient tracers, whereas the processes responsible for transport can be identified by environmental tracers such as temperature, salinity, dissolved oxygen and light transmissivity. In the following we first describe the use of transient and other environmental tracers for water age determination and for the characterization of water exchange processes. Then we discuss the application of these methods to Lake Issyk-Kul and present first tentative results on the mechanism of deep-water exchange based on data from two expeditions, one conducted in September 1996 and one in March 2001.

\subsection{TRANSIENT TRACERS}

The analysis of conservative trace gases, such as the noble gases ${ }^{3} \mathrm{He}[2][3],{ }^{222} \mathrm{Rn}[4]$, ${ }^{85} \mathrm{Kr}$ [5][6] and/or purely anthropogenic, persistent substances such as chlorofluorocarbons (e.g. CFC-11, CFC-12 [7]), sulphur hexafluoride ( $\mathrm{SF}_{6}[8]$ ) and tritium $\left({ }^{3} \mathrm{H}\right.$ [9]) provides a very powerful tool for tracing physical processes in the aquatic environment, because these transient tracers do not undergo biological or chemical transformation and their distribution in the environment is.therefore determined only by physical processes. Tracer concentrations and the isotopic composition of noble gases in water have been successfully employed to reconstruct soil temperature during groundwater recharge in the past $[10][11]$, to date young and old groundwaters $[2][3][12]$ and to analyse deep-water exchange in large lakes [13][14][15] and oceans 
[16]. All these experimental techniques, which were successfully developed by oceanographers over the last 25 years, today represent tools that are routinely used to determine the dynamics of aquatic systems.

In principle, two different dating methods can be distinguished. The first utilises the fact that certain atmospheric trace components, such as CFCs, ${ }^{85} \mathrm{Kr}$, and ${ }^{3} \mathrm{H}$, have a timedependent input function to the aquatic system. The atmospheric concentrations of these tracers have varied substantially over the last 50 years. Industrial production released most of the CFCs, especially CFC- 11 and CFC-12, to the atmosphere, whereas ${ }^{85} \mathrm{Kr}$ stems from nuclear fuel reprocessing plants. In the early 1960 s, nuclear bomb tests in the atmosphere increased the global tritium inventory by 2 to 3 orders of magnitude. The tritium concentration in precipitation has steadily decreased since the bomb-testing, but today tritium activity in meteoric water is usually still one order of magnitude larger than the expected background level due to tritium production by cosmic rays. If a given water parcel is in gas exchange with the atmosphere the observed concentration of a gaseous tracer reflects the atmospheric partial gas pressure at this time (Henry's Law). If the atmospheric partial pressure of the conservative gaseous tracer changes over time, the tracer concentration in the water parcel carries information about the time elapsed between the last gas exchange and the sampling date.

The second dating method is based on the phenomenon of radioactive decay. ${ }^{222} \mathrm{Rn}$ is produced by the decay of ${ }^{226} \mathrm{Ra}$, mainly bound in the sediments, from which Radon escapes to the water column. The short half-life of ${ }^{222} \mathrm{Rn}$ ( 3.86 days) leads to strong vertical concentration gradients in the water column which can be employed to determine mixing rates near the sediment/water interface [4].

The determination of the so-called ${ }^{3} \mathrm{H}-{ }^{3} \mathrm{He}$ water age' utilises the radioactive decay of ${ }^{3} \mathrm{H}$ to ${ }^{3} \mathrm{He}$. The half-life of tritium is 12.4 years. In a closed system, in which all concentration changes are solely the result of radioactive decay, the ratio of the concentration of the stable daughter isotope $\left({ }^{3} \mathrm{He}\right)$ to that of the radioactive mother isotope $\left({ }^{3} \mathrm{H}\right)$ yields a direct measure of the time elapsed since the water was last in contact with the atmosphere [2]. Note that ${ }^{3} \mathrm{H}-{ }^{3} \mathrm{He}$ dating does not depend on a knowledge of the atmospheric tritium input function.

In addition to dating aspects, the combined use of several transient tracers allows the problem of mixing processes in groundwater and open waters to be addressed (Fig. 1). Since the above-mentioned tracers are chemically and biologically inert, they trace only the physical transport in the water column of lakes. Thus chemical and biological transformations in the water column, e.g. oxygen depletion and gas exchange, can be separated out from the physical processes controlling the overall (deep) water exchange (advection and diffusion).

The various dating methods have very different links to the water body. CFCs and rare gas isotopes are dissolved as gases in the water, whereas tritium is bound in water molecules as HTO and is therefore part of the exchanged water itself. Since the influence of processes at the air/water interface on water molecules, on CFCs and on rare gases is different, the combination of tracer techniques allows the study of mixing processes within the water body and of the exchange at the air/water interface. 


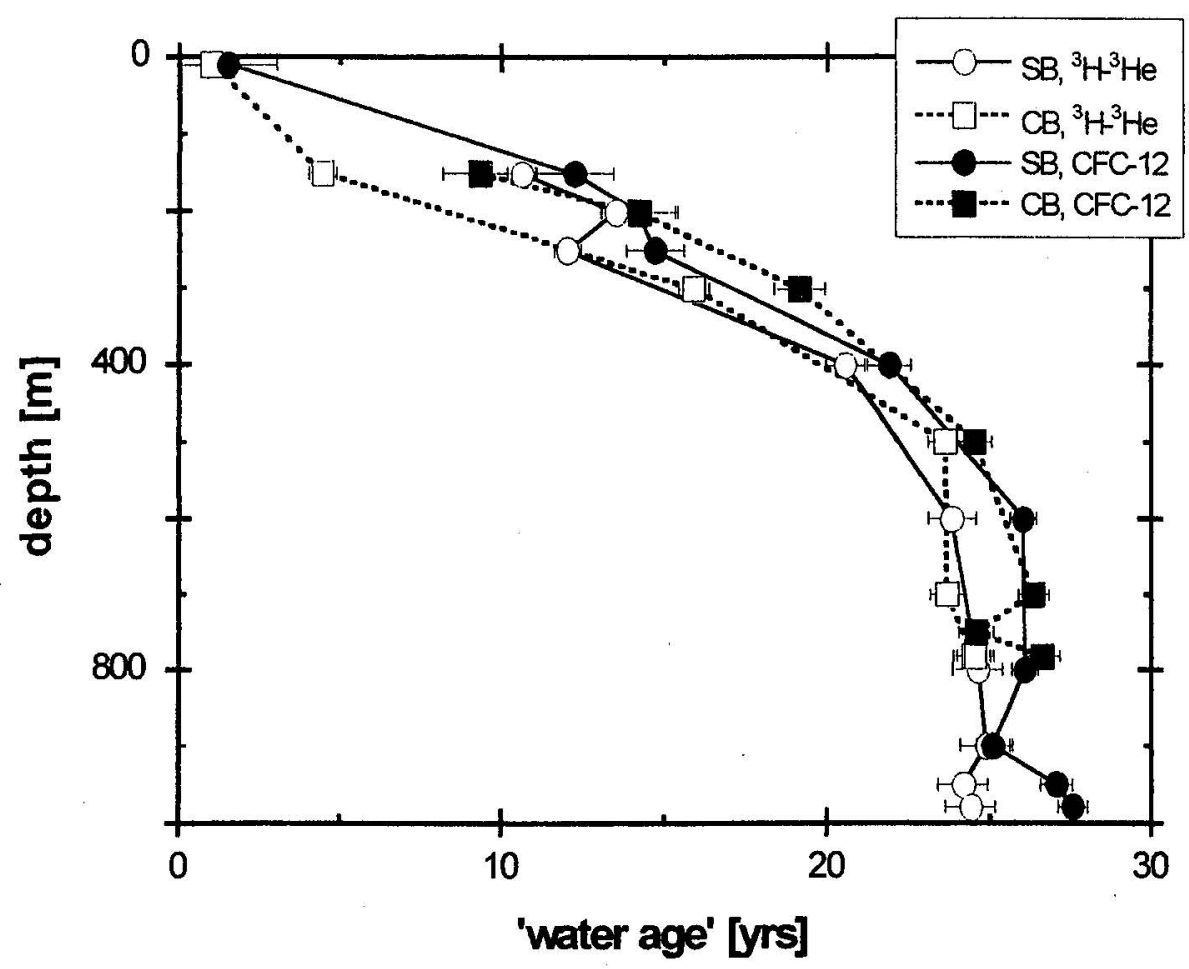

Figure 1: Water ages in the southern (SB) and central (CB) basins of the Caspian Sea derived from CFC-12 concentrations and the ${ }^{3} \mathrm{H}_{-}^{3} \mathrm{He}$ method. In both basins the water age of the deep water is the same and remains constant over time, suggesting similar mixing rates in the two basins. The difference in the water ages between surface and deep water has been used as a measure of the time required to exchange the water below $200 \mathrm{~m}$. This time of internal exchange is about 15 years and hence is significantly shorter than the time required by runoff and precipitation to (re)fill the Caspian Sea (Peeters et al. 2000).

\subsection{ENVIRONMENTAL TRACERS}

Temperature and salinity, which can be measured with high spatial resolution using modern CTD probes (conductivity, temperature, depth (pressure)), are commonly employed in oceanography and limnology to characterize water masses and to trace their transport trajectories. In contrast to most other substances that are used as tracers, temperature and salinity are non-passive, i.e. they have a major influence on water density and in consequence affect transport and mixing processes.

In addition to temperature and salinity, adequately equipped CTD probes can simultaneously record dissolved oxygen concentrations and light transmissivity. Oxygen is introduced into the water body via gas exchange at the air/water interface and by primary production in the euphotic zone in the uppermost part of the water column. Oxygen depletion occurs in the deeper part of the water column and in particular at the sediment/water interface as a result of the mineralisation of organic matter. Consequently, oxygen concentrations commonly decrease with increasing depth, resulting in 
gentle concentration gradients. Deviations from rather smooth oxygen gradients toward larger values indicate the presence of oxygen-rich surface water and hence also indicate active deep-water exchange.

Light extinction occurs in waters mainly due to the presence of suspended particles from various sources. Hence light transmission decreases as the load of suspended particles in the water column increases. Often a decrease in light transmission can be interpreted to indicate either riverine inflow containing a high particle load or the remobilisation of particles from the sediments. Note that suspended particles also affect the water density and therefore cannot be considered passive.

\section{The Use of Tracers to Study Deep-Water Mixing in Lake Issyk-Kul}

According to historical data, deep-water temperatures at $600 \mathrm{~m}$ depth and below always range between $3.7-4.2^{\circ} \mathrm{C}$ [17] and hence are significantly higher than the temperature at which Issyk-Kul water has its maximum density $\left(T_{m d}\right)$. Since the mean salinity in the open water of Issyk-Kul is close to 6.0 per mille (calculated from the chemical composition given by Tsigelnaya [18]) $\mathrm{T}_{\mathrm{md}}$ is approximately $2.6^{\circ} \mathrm{C}$ at surface pressure. The value $T_{m d}=2.75^{\circ} \mathrm{C}$ given in Romanowski [17] might be based on a slightly smaller salinity. In any case, $T_{m d}$ at the lake surface is lower than the deep-water temperatures. For surface temperatures down to $2.6^{\circ} \mathrm{C}$ the thermal expansion coefficient $\square=-\square^{\circ}$ ${ }^{1} \partial \square / \partial \mathrm{T}>0$ in the entire water column. Thus seasonal cooling at the lake surface down to $\mathrm{T}_{\mathrm{md}}$ leads to an increase in the density of the surface water and can generate large-scale vertical convection down to the deepest parts of the lake, probably resulting in fast renewal of the water below $400 \mathrm{~m}$. This hypothesis is supported by the existence of very high concentrations of dissolved oxygen - close to atmospheric equilibrium - throughout the water column ([19] and Fig. 2) and by the brownish colour of the topmost $15 \mathrm{~cm}$ of sediment cores indicating oxygenated sediments (Santiago Giralt, personal communication). In addition, in winter 1976 tritium concentrations were found to be homogeneous throughout the water column with the exception of the bottom $50 \mathrm{~m}$ [20], indicating that mixing had already smoothed out the tritium bomb-peak of 1963 . This suggests that the residence time in the deep water can be expected to be less than 13 years.

Because atmospheric CFC concentrations have not changed significantly since 1996, measurements of CFCs in 2001 or later cannot provide reliable information on residence times shorter than 5 years. Thus, CFCs are possibly only of limited value for the study of mixing processes in Lake Issyk-Kul. However, the tracer $\mathrm{SF}_{6}$ might provide detailed information on residence times because its atmospheric concentration is still increasing strongly with time. Alternatively, the ${ }^{3} \mathrm{H}-{ }^{3} \mathrm{He}$ method might be employed, because it is capable of resolving water ages ranging from one month to several decades. This suggests that $\mathrm{SF}_{6}$ and ${ }^{3} \mathrm{He}$ and ${ }^{3} \mathrm{H}$ will be the most promising tracer combination to allow a reliable quantification of deep-water residence times and deep-water exchange in Lake Issyk-Kul. 

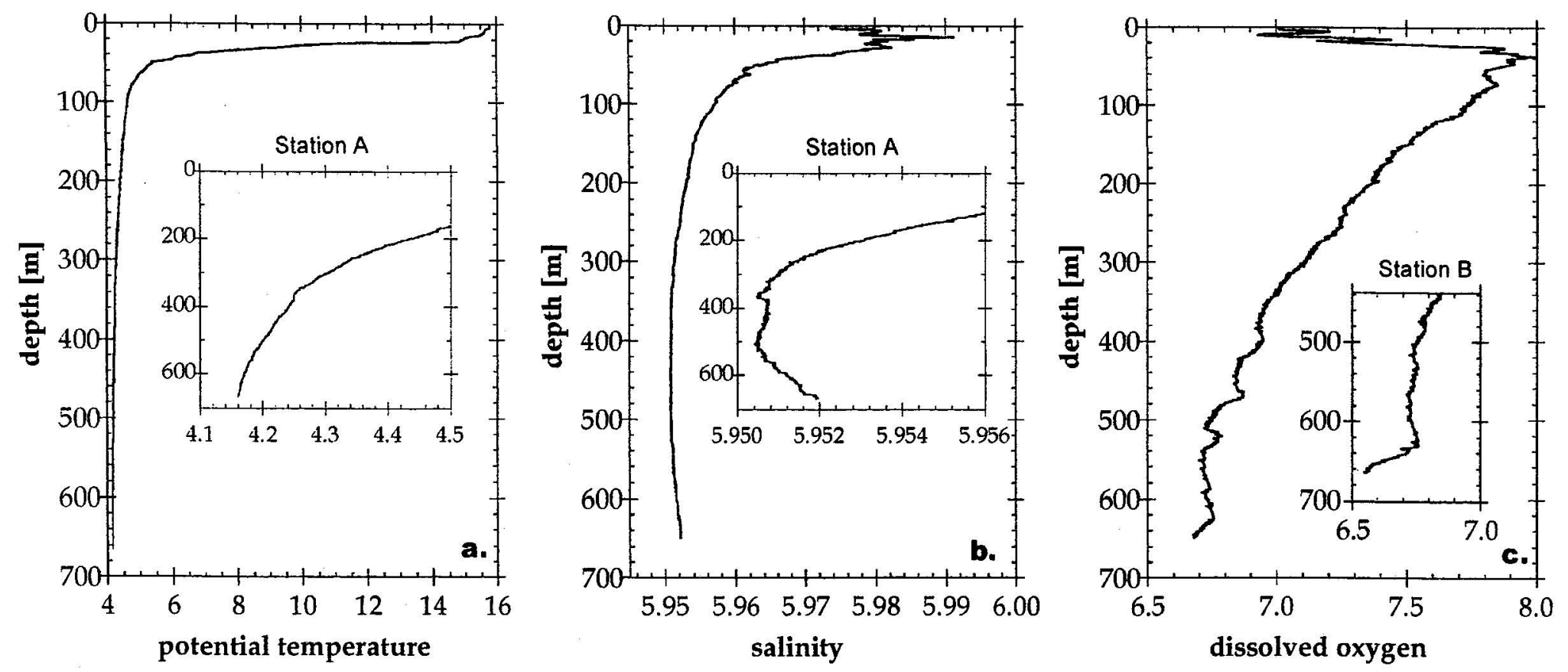

Figure 2: Potential temperature, salinity and dissolved oxygen measured in the deep central part of Lake Issyk-Kul in September 1996 (Station A). The insets in Fig.2a and b show the profiles in more detail, whereas in Fig. 2c the inset shows the deep section of dissolved oxygen measured at station $\mathrm{B}$. Note that the $\mathrm{O}_{2}$ data stem from a sensor for dissolved oxygen and have not been calibrated by chemical measurements. 


\section{Preliminary Results from CTD Measurements}

A first attempt to characterize the processes responsible for deep-water exchange based on high-resolution CTD measurements was undertaken in September 1996 (Fig. 2). With increasing depth, potential temperature decreases steadily down to $4.16^{\circ} \mathrm{C}$. Because the temperature profile shows a minimum at the largest depth, advective transport processes must play a major role in venting even the deepest region of Lake Issyk-Kul.

Salinity was calculated from conductivity using the UNESCO equations for ocean waters [21]. This procedure underestimates the absolute values of salinity and overestimates the effect of pressure on conductivity because the ion composition of Issyk-Kul water [18] differs from that of the ocean on which the UNESCO equations are based. We therefore applied an additional calibration factor and a pressure correction which will be described elsewhere.

Except for the uppermost $30 \mathrm{~m}$, salinity is rather constant throughout the water column. Whether the slight increase in salinity with depth below $400 \mathrm{~m}$ (Fig.2b) is real or is an artefact of the applied pressure correction cannot be determined. Temperature and salinity profiles are fairly smooth and give no indication of lateral intrusions except possibly at $350 \mathrm{~m}$ depth. The profile of dissolved oxygen, however, has distinct structures at depths $400 \mathrm{~m}, 470 \mathrm{~m}$ and $520 \mathrm{~m}$ (Fig. 2c) that suggest the lateral inflow of oxygen-rich waters. In all 6 profiles measured at deep stations in September 1996, dissolved oxygen concentrations decrease with depth in the near-bottom waters immediately above the sediments. In most profiles the decrease with depth is more pronounced than at station A and similar to that measured at station B (Fig 2c, inset). This specific feature in the vertical $\mathrm{O}_{2}$ distribution is most likely related to mineralisation processes at the sediment-water interface, which become the dominant factor of oxygen consumption near the lake bottom due to the large sediment area to water volume ratio. In Fig. 2 the $\mathrm{O}_{2}$ concentrations are not calibrated by chemical measurements and thus might be shifted relative to the corresponding true absolute values. However, the relative changes within the $\mathrm{O}_{2}$ profile indicate that dissolved oxygen might be the tracer of choice to study advective transport processes and intrusions in Lake Issyk-Kul.

Temperatures measured in September 1996 along a transect from north to south through the centre of the lake at about $77.06^{\circ} \mathrm{E}$ indicate warm water in the shallow near-shore regions (Fig. 3). At the same depths the water in the centre of the lake is significantly colder than the near-shore water. This general temperature structure has already been described in the literature [22] as a doming effect and has been interpreted to indicate the large-scale upwelling of cold water in the open lake. According to Romanowski and Shabunin [22] the prevailing cyclonic wind field leads to the downwelling of warm water in the coastal regions and the upwelling of cold water in the open lake. Note that this process appears to be limited to the top $100-200 \mathrm{~m}$ (Fig. 3), probably because density stratification hinders a deeper penetration of the warm downwelling water. In addition to the dynamic process outlined above, differential warming of the near-shore regions during the warm season might enhance the temperature difference between open and coastal regions. 


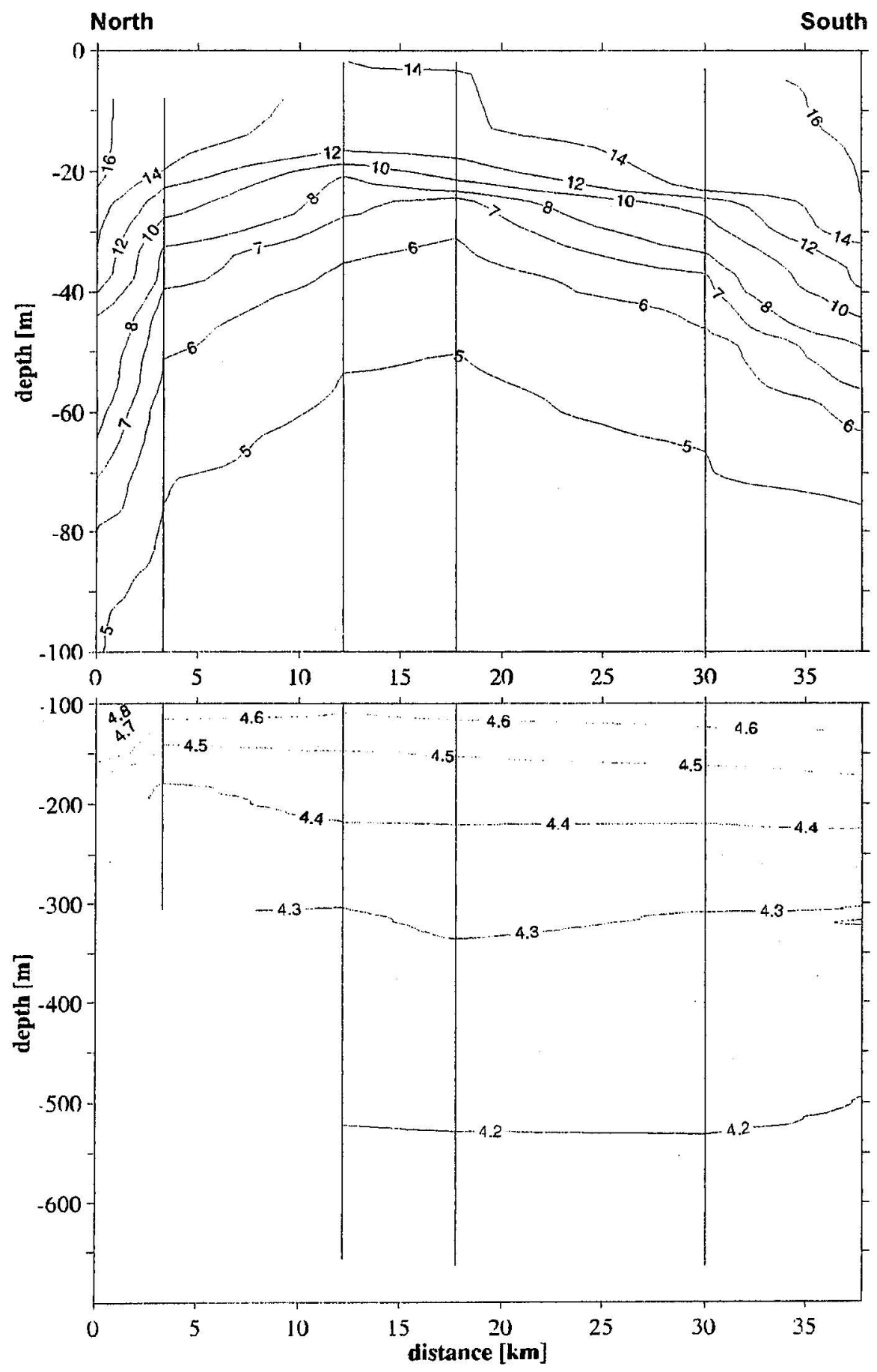

Figure 3: Distribution of potential temperature along a North-South transect about $77.06^{\circ} \mathrm{E}$ through the deepest part of Lake Issyk-Kul. The upper panel shows the temperature distribution in the $0-100 \mathrm{~m}$ depth range and the lower panel the temperature distribution below $100 \mathrm{~m}$. Note that the intervals between the temperature isolines, given in $\left[{ }^{\circ} \mathrm{C}\right]$, are different in the two panels. 
Because during the warm season temperatures at shallow depths are significantly higher than those of the deep water, advective processes transporting oxygen-rich surface water to very large depths can only be driven by salt gradients or gradients in suspended particle load. The former might be generated by evaporation in shallow bays, whereas the latter could be caused by inflowing meltwater from glaciers. However, it is unlikely that significant deep-water convection occurs during the warm season because of the strong temperature gradients, which imply strong density gradients.

Deep-water exchange should be expected to occur in the cold season between late autumn and early spring, when surface temperatures are low and vertical temperature gradients and the corresponding density gradients are small. In winter 1976, Romanov et al. [20] observed a strong increase in tritium activity in the lowermost $50 \mathrm{~m}$ of the open water column, indicating the lateral input of tritium-rich water which must originate from upper regions of the water body ('mixing around the edge'). Similar observations are known from Lake Baikal, where near-bottom anomalies in tracer concentrations are caused by massive advective deep-water exchange [23][24][14].

Further evidence for strong advective mixing in spring was found in March 2001 (Fig 4). Profiles from two CTD casts are shown (dotted and solid lines) which were taken within 75 minutes of one another at a distance of less than $2.5 \mathrm{~km}$ apart. The distinct differences between the profiles indicate that the conditions in Lake Issyk-Kul in spring are spatially and/or temporally very inhomogeneous. Dissolved oxygen and light transmissivity profiles at station 8 (solid lines) show distinct features which are correlated and apparently characterize water masses which are transported from shallow depths to the deepest regions of the lake, as indicated by the high oxygen concentrations. Fig. 4 demonstrates that, in addition to dissolved oxygen, light transmissivity proves to be an excellent tracer for the identification and characterization of convective processes in Lake Issyk-Kul.

Comparison of the salinity profiles from stations 7 and 8 measured in 2001 (Fig. 4) indicates several intrusions. At around $550 \mathrm{~m}$, for instance, the intruding water at station 8 has a higher salinity than that at station 7 . Associated with the salinity peak are values of temperature, $\mathrm{O}_{2}$ concentration and suspended particle load (inversely related to light transmissivity) that are higher than background values. This suggests that the water at $550 \mathrm{~m}$ depth at station 8 originates from shallower depths where $\mathrm{O}_{2}$ concentrations and suspended particle loads are generally higher.

At both stations salinity appears to be highest at intermediate depths. Possibly this intermediate salinity maximum is related to intruding higher-salinity water from shallower regions, where evaporation during the warm season has resulted in increased salt concentrations. However, as mentioned before, the salinity maximum at intermediate depth might not be real, but instead be the result of the imperfect empirical relations employed to calculate salinity from conductivity.

The change in the absolute values of salinity from 1996 to 2001 is most likely due to the use of different conductivity sensors in the two expeditions. The salinity difference between 1996 and 2001 suggested by the CTD measurements are smaller than measurable by chemical methods and can therefore not be tested independently. 

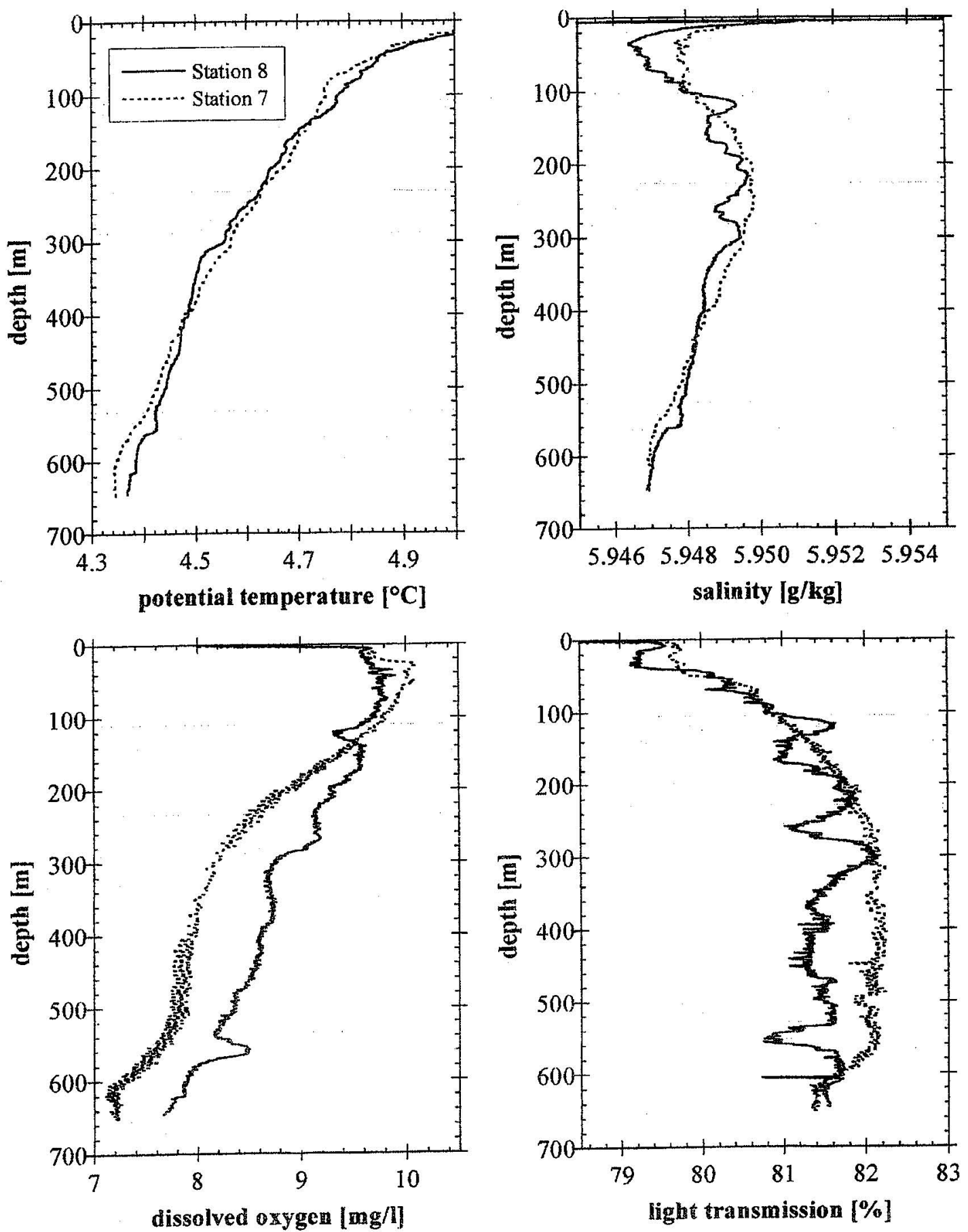

Figure 4: Potential temperature, salinity, dissolved oxygen and light transmissivity measured in March 2001 in Lake Issyk-Kul. The data stem from two CTD casts (station 8, solid line; station 7 , dotted line) which were taken within 75 minutes of one another at a distance of less than 2.5 $\mathrm{km}$. The $\mathrm{O}_{2}$-sensor measurements agree well with the concentration of dissolved $\mathrm{O}_{2}$ determined by Winkler titration 


\section{Conclusions}

In addition to the classical tracers temperature and salinity, dissolved oxygen and light transmissivity are key variables in the study of processes leading to deep-water renewal in Lake Issyk-Kul. Deep-water exchange most likely occurs predominantly in winter and spring, when temperature gradients are small. Clear evidence for rapid deep-water mixing in spring is provided by CTD profiles measured in March 2001. During the summer season, vertical advection might be driven by salinity gradients generated by evaporation in shallow bays. Vertical mixing at shallower depths is probably dominated by wind-driven processes leading to downwelling in coastal areas and upwelling in the open water [22]. Homogeneous tritium concentrations in 1976 [20] and high values of dissolved oxygen close to atmospheric equilibrium concentration throughout the water column suggest that deep-water residence times must be rather short. Therefore, the combination of the tracer $\mathrm{SF}_{6}$ with the ${ }^{3} \mathrm{H}-{ }^{3} \mathrm{He}$ method would appear to be the most suitable approach to quantify reliably deep-water exchange in Lake Issyk-Kul.

\section{Acknowledgements}

Thanks are due to Prof. Jan Klerkx and Santiago Giralt for making available the CTD data from the 1996 expedition to Lake Issyk-Kul. This research was made possible by funding from the Swiss Federal Office of Education and Science (BBW; Contract No. 99.0720) within the framework of the European INCO/COPERNICUS Project APELIK ('Assessment and Prognosis of Environmental Changes in Lake Issyk-Kul (Kyrgyzstan)'; Contract No. ICA2-CT-2000-10003

\section{References}

1. Imboden,D.M. (1990) Mixing and transport in lakes: Mechanisms and ecological relevance, in M. Tilzer and C. Serruya (eds.), Large Lakes: Ecological Structure and Function., Springer, Berlin, pp. 47-80.

2. Tolstikhin, I. N., Kamenskiy, I. L. (1969) Determination of ground-water ages by the $\mathrm{T}-{ }^{3} \mathrm{He}$ Method. Geochemistry International 6, 810-811.

3. Schlosser, P. (1992) Tritium/3He dating of waters in natural systems. Isotopes of noble gases as tracers in environmental studies, Vienna, IAEA.

4. Imboden, D.M., Emerson, S. (1978) Natural radon and phosphorus as limnologic tracers: Horizontal and vertical eddy diffusion in Greifensee. Limnol. Oceanogr. 23, 77-90.

5. Loosli, H.H., Oeschger, H. (1979) Argon-39, carbon-14 and krypton-85 measurements in groundwater samples, IAEA, Ed., Isotope Hydrology 1978, Neuherberg IAEA.

6. Loosli, H.H., Lehmann, B.E., Balderer, W. (1998) Argon-39, argon-37 and krypton85 isotopes in Stripa groundwaters. Geochim. Cosmochim. Acta 53, 1825-1829. 
7. Dunkle, S. A., Plummer, L. N., Busenberg, E., Phillips, P. J., Denver, J. M., Hamilton, P. A., Michel, R. L., Coplen, T. B. (1993) Chlorofluorocarbons $\left(\mathrm{CCl}_{3} \mathrm{~F}\right.$ and $\mathrm{CCl}_{2} \mathrm{~F}_{2}$ ) as dating tools and hydrologic tracers in shallow groundwater of the Delmarva Peninsula, Atlantic Coastal Plain, United States. Water Resour. Res. 29, 3837-3860.

8. Busenberg, E. and Plummer, L. N. (2000) Dating young groundwater with sulfur hexafluoride: natural and anthropogenic sources of sulfur hexafluoride, Water Resour. Res. 36, 3011-3030.

9. Münnich, K.O., Roether,W., Thilo, W. (1967) Dating of groundwater with tritium and ${ }^{14} \mathrm{C}$. IAEA, Ed., Isotope Hydrology, Vienna, 19, 305-320.

10. Stute, M., Clark, J. F., Schlosser, P., Broecker, W. S. (1995) A 30,000 yr continental paleotemperature record derived from noble gases dissolved in groundwater from the San Juan Basin, New Mexico. Quatern. Res. 43, 209-220.

11. Beyerle, U., Purtschert, R., Aeschbach-Hertig, W., Imboden, D. M., Loosli, H. H., Wieler, R., Kipfer, R. (1998) Climate and groundwater recharge during the last glaciation in an ice-covered region, Science 282, 731-734.

12. Beyerle, U., Aeschbach-Hertig, W., Hofer, M., Imboden, D.M., Baur, H., Kipfer, R. (1999) Infiltration of river water to a shallow aquifer investigated with ${ }^{3} \mathrm{H} /{ }^{3} \mathrm{He}$, noble gases and CFCs. J. Hydrol. 220, 169-185.

13. Aeschbach-Hertig, W., Kipfer, R., Hofer, M., Imboden, D. M., Baur, H. (1996) Density-driven exchange between the basins of Lake Lucerne (Switzerland) traced with the ${ }^{3} \mathrm{H}-{ }^{3} \mathrm{He}$ method. Limnol. Oceanogr. 41, 707-721.

14. Hohmann, R., Hofer, M., Kipfer, R., Peeters, F., Imboden, D.M. (1998) Distribution of helium and tritium in Lake Baikal. J. Geophys. Res. 103, 1282312838.

15. Peeters, F., Kipfer, R., Achermann, D., Hofer, M., Aeschbach-Hertig, W., Beyerle, U., Imboden, D. M., Rozanski, K., Fröhlich, K. (2000) Analysis of deep-water exchange in the Caspian Sea based on environmental tracers. Deep-Sea Res. I 47, 621-654.

16. Jenkins, W.J. (1976) Tritium-helium dating in the Sargasso Sea: A measurement of oxygen utilization rates. Science, 196, 291-292.

17. Romanowski, V. V. (1991) Lake Issyk-Kul as natural system. Frunze (in Russian).

18. Tsigelnaya, I. D. (1995) Issyk-Kul Lake, in A.F. Mandych (ed.), Enclosed seas and large lakes of eastern Europe and middle Asia. SPB Academic Publishing.

19. Kadyrov, V. K. (1986) Hydrochemistry of the Lake Issyk-Kul and its basin. Ilim Publishing House, Frunze, p. 212. (in Russian)

20. Romanov, V., Vlasova, L. S., Meskheteli, A. V., Salnova, L. V (1989) A Tritium study of the formation of natural waters of Issykul basin, Water Resources, 4, 82 94 (in Russian).

21. UNESCO, ICES, SCOR, and IAPSO, (1981) Background papers and supporting data on the practical salinity scale 1978. Unesco technical papers in marine science, Nr. 37, UNESCO. 
22. Romanowski, V. V., Shabunin, G. (1981) Upwelling in Lake Issyk-Kul. In: Dynamics of modern coastal processes in Lake Issyk-Kul, Ilim Publishing House, Frunze, 160-169 (in Russian).

23. Weiss, R. F., Carmack, E. C., Koropalov, V. M. (1991) Deep-water renewal and biological production in Lake Baikal, Nature, 349, 665-669.

24. Hohmann, R., Kipfer, R., Peeters, F., Piepke, G., Imboden, D.M., Shimaraev, M.N. (1997) Processes of deep-water renewal in Lake Baikal. Limnol. Oceanogr. 42, 841855.

25. Imboden, D.M., Lemmin, U., Joller, T., Schurter, M. (1983) Mixing processes in lakes: Mechanisms and ecological relevance. Schweiz. Z. Hydrol. 45, 11-44. 